\title{
Susceptibility to short-term ozone exposure and cardiovascular and respiratory mortality by previous hospitalizations
}



\begin{abstract}
Background: Ozone $\left(\mathrm{O}_{3}\right)$ has been associated with cardiorespiratory mortality although few studies have explored susceptible populations based on prior disease.

We aimed to investigate the role of previous hospitalization on the association between short-term exposure to $\mathrm{O}_{3}$ and cardiovascular (CV) and respiratory mortality.

Methods: We performed time series analyses using generalized additive models and case-crossover on 136,624 CV and 23,281 respiratory deaths in Stockholm County (1990-2010). Deaths were linked to hospital admissions data. We constructed 2-day and 7-day averages using daily 8-h maximum for $\mathrm{O}_{3}$ and hourly values for $\mathrm{PM}_{2.5}, \mathrm{PM}_{10}, \mathrm{NO}_{2}$, and $\mathrm{NO}_{x}$ from a fixed monitor.

Results: We observed a $0.7 \%$ (95\% Cl: $0.1 \%, 1.3 \%)$ and $2.7 \%$ (95\% Cl: 0.8\%, 4.6\%) higher risk of CV and respiratory death per $10 \mathrm{\mu g} / \mathrm{m}^{3}$ higher 2-day and 7-day average $\mathrm{O}_{3}$ respectively. Individuals previously hospitalized for myocardial infarction demonstrated 1.8\% (95\% Cl: 0.4\%, 3.4\%) higher risk of CV death per $10 \mu \mathrm{g} / \mathrm{m}^{3}$ higher 2-day average $\mathrm{O}_{3}$ and similar associations were observed in individuals with no previous hospitalization for any cause. Individuals with previous hospitalizations did not show susceptibility towards $\mathrm{O}_{3}$-related risk of respiratory mortality. We observed no associations for other pollutants.

Conclusion: Short-term ozone exposure is associated with CV and respiratory mortality and our results may suggest higher susceptibility to $\mathrm{CV}$ mortality following $\mathrm{O}_{3}$ exposure in individuals previously hospitalized for myocardial infarction. Higher risks were also observed in individuals with cardiovascular death as their first presentation of disease.
\end{abstract}

Keywords: Air pollution, Cardiovascular deaths, Respiratory deaths, Susceptibility

\section{Background}

Higher levels of ambient Ozone $\left(\mathrm{O}_{3}\right)$ have been associated with cardiovascular $(\mathrm{CV})$ and respiratory mortality $[1,2]$. Severity of health effects of $\mathrm{O}_{3}$ experienced by individuals with pre-existing diseases or other determinants may be larger than among other individuals [3]. Knowledge on susceptible populations is important for providing relevant guidelines for air quality standards protecting significant susceptible groups within the general population. In an attempt to identify such groups, some studies have explored age differences and reported elderly [3-6] and

\footnotetext{
* Correspondence: auriba.raza@ki.se; auriba@gmail.com

${ }^{1}$ Institute of Environmental Medicine, Karolinska Institutet, Nobels väg 13 |

Box 210 |, SE-171 77 Stockholm, Sweden

Full list of author information is available at the end of the article
}

children [7] as populations with higher risk. Susceptibility according to sex or other sociodemographic characteristics $[3,4,8]$ have also been explored but with mixed results. Previous studies that have explored the impact of pre-existing diseases on the susceptibility to $\mathrm{O}_{3}$ mortality have for example used surrogates for pre-existing diseases using secondary diagnosis of death [3] or have considered total mortality rather than cause-specific mortality, both factors affecting accurate identification of susceptible populations $[3,6,8,9]$. The pre-existing diseases that conferred increased susceptibility in these studies were not fully consistent from study to study but centered around diabetes, atrial fibrillation and atherosclerotic diseases. In addition, there is some evidence to suggest

(c) The Author(s). 2018 Open Access This article is distributed under the terms of the Creative Commons Attribution 4.0 International License (http://creativecommons.org/licenses/by/4.0/), which permits unrestricted use, distribution, and reproduction in any medium, provided you give appropriate credit to the original author(s) and the source, provide a link to the Creative Commons license, and indicate if changes were made. The Creative Commons Public Domain Dedication waiver (http://creativecommons.org/publicdomain/zero/1.0/) applies to the data made available in this article, unless otherwise stated. 
that susceptibility factors to $\mathrm{O}_{3}$ mortality are more important in cities with low air pollution concentrations [3].

Illness related to $\mathrm{CV}$ or respiratory diseases resulting in hospitalizations such as ischemic heart disease events, exacerbations of chronic obstructive lung disease (COPD), and diabetes are likely to be harbingers of $\mathrm{CV}$ or respiratory mortality and may be markers of susceptibility to the effects of $\mathrm{O}_{3}$. In a previous study from Stockholm, we observed association between 2-day levels of $\mathrm{O}_{3}$ and risk of non-traumatic mortality and this risk was higher among individuals with previous hospitalizations for acute myocardial infarction (AMI) [8]. We therefore hypothesized that individuals with previous hospitalizations for AMI, other CV diseases, respiratory diseases, and diabetes would carry higher risks of $\mathrm{CV}$ mortality per incremental increase in short-term $\mathrm{O}_{3}$ exposure compared to the risk in the overall population. Likewise, we hypothesized that individuals with previous hospitalizations for COPD, pneumonia, or other respiratory diseases would carry higher risks of respiratory mortality per incremental increase of short-term $\mathrm{O}_{3}$ exposure compared to the risk in the overall population. Consequently, in the present study we aimed to investigate the role of previous hospitalizations on the associations between short-term exposure to $\mathrm{O}_{3}$ and $\mathrm{CV}$ and respiratory mortality. In the setting of the low-level pollution environment of Stockholm, Sweden, we made use of the well-validated Swedish death registry and inpatient registry [10] to include all deaths in Stockholm and all hospitalizations in Sweden to study these associations using continuous monitoring of ambient air pollution concentrations.

\section{Methods}

\section{Study population}

We included residents of Stockholm County older than 30 years with $\mathrm{CV}$ or respiratory deaths occurring in the County from 1990 to 2010. We obtained age, sex, date and cause of death, and all dates and diagnoses of hospitalizations from the Swedish Board of Health and Welfare with mortality and hospitalizations data available from 1990 and 1987, respectively. We linked all CV and respiratory deaths to all previous hospitalizations in Sweden up to 3 years before death to create susceptible groups based on the principal diagnosis code (International Classification of Diseases, Ninth Revision (ICD9) and Tenth Revision (ICD-10) at discharge (Table 1). In a previous study, hospitalizations prior to 3 years before death did not identify a population sensitive to air pollution related overall mortality [8] and therefore we chose a 3 year period for previous hospitalizations in order to have a uniform hospitalization period for all individuals.

Table 1 Characteristics and categorization of cardiovascular (ICD-9 390-459; ICD-10 I00-I99) and respiratory (ICD-9 460-519; ICD10 J00-J99) deaths by previous admissions for diseases among Stockholm County residents $\geq 30$ years old, 1990-2010

\begin{tabular}{|c|c|c|c|c|c|c|}
\hline \multirow[t]{2}{*}{ Categorization of mortality } & \multicolumn{2}{|c|}{ Diagnosis of hospital admission } & \multirow[t]{2}{*}{ Total } & \multirow[t]{2}{*}{ Percent } & \multirow{2}{*}{$\begin{array}{l}\text { Mean } \\
\text { age } \\
\text { (SD) } \\
\end{array}$} & \multirow{2}{*}{$\begin{array}{l}\text { Female } \\
(\%)\end{array}$} \\
\hline & $\mathrm{ICD}-9$ & ICD-10 & & & & \\
\hline A. Total cardiovascular deaths & & & 136,624 & 100 & $81(10)$ & 54.1 \\
\hline \multicolumn{7}{|l|}{ Individuals previously hospitalized for } \\
\hline i) $\mathrm{AMl}$ & 410 & $121-122$ & 20,948 & 15.0 & $81(11)$ & 47.3 \\
\hline ii) Non-AMI CVD & $390-409,411-459$ & $100-120,123-199$ & 60,346 & 44.2 & $81(10)$ & 54.7 \\
\hline iii) Respiratory diseases & $460-519$ & J00-J99 & 5919 & 4.4 & $81(10)$ & 51.2 \\
\hline iv) Diabetes & 250 & E10-E14 & 1081 & 1.0 & $81(10)$ & 51.4 \\
\hline v) Other diseases & All except above & All except above & 24,283 & 18.0 & $81(10)$ & 60.1 \\
\hline vi) Not hospitalized in 0-3 years ${ }^{\mathrm{a}}$ & & & 16,190 & 12.0 & $83(11)$ & 58.0 \\
\hline vii) Not hospitalized since 1987 & & & 7417 & 5.4 & $73(13)$ & 41.2 \\
\hline B. Total respiratory deaths & & & 23,281 & 100 & $80(10)$ & 53.1 \\
\hline \multicolumn{7}{|l|}{ Individuals previously hospitalized for } \\
\hline i) $\mathrm{COPD}$ & $490-496$ & $J 40-J 47, J 67$ & 5774 & 25.0 & $80(11)$ & 52.6 \\
\hline ii) Pneumonia & $480-486$ & $J 12-J 18$ & 6003 & 26.0 & $79(11)$ & 45.6 \\
\hline iii) Other respiratory diseases & $460-480,486-490,497-519$ & J00-J11, J19-J40, J48-J66, J68-J99 & 1648 & 7.0 & $80(11)$ & 49.8 \\
\hline iv) Other diseases & All except above & All except above & 6774 & 29.0 & $79(11)$ & 56.4 \\
\hline v) Not hospitalized in 0-3 years ${ }^{a}$ & & & 2442 & 10.0 & $84(11)$ & 65.8 \\
\hline vi) Not hospitalized since 1987 & & & 640 & 3.0 & $80(14)$ & 54.0 \\
\hline
\end{tabular}

Note: All categories are mutually exclusive

${ }^{a}$ These individuals had hospitalizations between 1987 and up to 3 years preceding their death but not in the 3 years preceding death 


\section{Categorization by previous hospitalization}

For individuals who died a CV death, we defined susceptibility based on hospitalizations for i) acute myocardial infarction (AMI; ICD-9 410, ICD-10 I21-I22); ii) all other cardiovascular diseases (CVD; ICD-9 390-409, 411-459, ICD-10 I00-20, I23-99), excluding individuals who had AMI; iii) respiratory diseases (ICD-9 460-519, ICD10 J00-99), excluding individuals with CVD; iv) diabetes (ICD-9 250, ICD-10 E10-14), excluding individuals with CVD and respiratory diseases; v) other diseases, excluding individuals who have been hospitalized for CVD, respiratory diseases, and diabetes; vi) individuals who were not hospitalized between 0 and 2 years before death for any disease but had earlier hospitalizations; and vii) individuals who died cardiovascular death but had not been hospitalized since 1987 for any cause.

For individuals who died a respiratory death, we defined susceptibility based on hospitalizations for i) chronic obstructive pulmonary disease (COPD; ICD9 490-496, ICD-10 J40-47, J67); ii) pneumonia (ICD9 480-486, ICD-10 J12-J18), excluding individuals who had hospitalizations for COPD; iii) other respiratory diseases (ICD-9 460-480, 486-490, 497-519, ICD-10 J0011, J19-40, J48-66, J68-99), excluding individuals who had been hospitalized for COPD and pneumonia; iv) any disease other than respiratory disease; $v$ ) not hospitalized between 0 and 2 years but had earlier hospitalizations; and vi) individuals with respiratory deaths but no record of previous hospitalizations since 1987 for any cause.

In an effort to avoid double counting of individuals with multiple hospitalizations in different hospitalization categories we followed the above-mentioned hierarchies to ensure mutually exclusive groups. Only one hospitalization was considered for each individual and category. Count data was created per day for each mortality outcome and further stratified by categories of previous hospitalizations.

\section{Air pollution and meteorological data}

Exposure data was provided by the Stockholm-Uppsala County Air Quality Management Association. We identified a priori $\mathrm{O}_{3}$ as our main exposure of interest based on our previous study and included exposure data for Nitrogen dioxide $\left(\mathrm{NO}_{2}\right)$, Nitrogen oxides $\left(\mathrm{NO}_{\mathrm{x}}\right)$, particles with aerodynamic diameter smaller than 2.5 and $10 \mu \mathrm{m}\left(\mathrm{PM}_{2.5}\right.$ and $\mathrm{PM}_{10}$ ) for comparison with other studies. Hourly means of $\mathrm{O}_{3}, \mathrm{NO}_{2}, \mathrm{NO}_{\mathrm{x}}, \mathrm{PM}_{2.5}, \mathrm{PM}_{10}$, temperature and relative humidity were obtained from a single centrally located urban background monitoring station.

For $\mathrm{O}_{3}$, we first calculated an 8-h running mean over 24-h period to compute an 8-h maximum. We calculated 24-h averages of $\mathrm{NO}_{2}, \mathrm{NO}_{\mathrm{x}}, \mathrm{PM}_{2.5}, \mathrm{PM}_{10}$, temperature, and relative humidity from hourly values.

\section{Statistical analysis}

We performed both time series and case-crossover analyses to analyze associations between air pollutants and the risk of cause-specific mortality in those with and without previous hospitalizations. In time series, we employed generalized additive models based on quasi-Poisson distribution. These models were adjusted for long-term and seasonal trends, temperature, relative humidity, daily influenza hospital admissions, day of the week, and public holidays. We modeled seasonal and long-term time trend by penalized splines with 5 degrees of freedom (df) per year; holidays and day of week as indicator variables; the mean values of the relative humidity during the day of death and previous day as linear terms; the mean values of the temperature during the day of death and previous day as cubic splines with 3 degrees of freedom; and a 7-day running average of daily influenza admissions in Stockholm as cubic spline with $4 \mathrm{df}$.

For comparison we also employed the case-crossover analyses for both the main effects assessing associations between $\mathrm{O}_{3}$ exposure and $\mathrm{CV}$ or respiratory mortality and to estimate the presence of effect modification by season, age, sex, and susceptibility by previous hospitalizations using multiplicative terms including $\mathrm{O}_{3}$ and the specific effect modifier in separate models. We used a time stratified referent selection strategy with conditional logistic regression. Control periods were matched with case periods on same day of the week, within the same calendar month, and year as the day of death. This way, time trend and slowly changing individual characteristics were adjusted by the design. We adjusted for temperature and daily influenza hospital admissions as a restricted cubic spline with 2 degrees of freedom (df) and relative humidity as a linear term. Age was dichotomized by median age at the time of death and season by warm (April to September) and cold (October to March) season. For susceptibility by previous hospitalization, we performed a likelihood ratio test to compare the model with an interaction term including hospitalization categories (using the largest category as the reference) with the reduced model without the covariate containing the hospitalization categories.

We used a $0-1$ day lag ( 2 day average) and 0-6 day lag (7-day average) in single-pollutant models in our initial analysis based on evidence from previous studies indicating most apparent effects both within the immediately preceding days and up to a week $[5,6]$. We then selected a lag for subsequent analyses of $\mathrm{CV}$ and respiratory mortality that demonstrated the strongest association, in separate models, assessed by largest effect estimates with statistical significance. We also evaluated two-pollutant models to adjust for other pollutants. We then proceeded with stratified analyses of $\mathrm{CV}$ and respiratory mortality according to previous hospitalizations in time series analyses and separately employed the whole dataset in 
case-crossover analyses using a multiplicative term for $\mathrm{O}_{3}$ and hospitalization category.

In sensitivity analyses, we controlled for the effects of temperature over longer periods using averaging times of 0-6 days for temperature. Our cause-specific mortality data starts from 1990 and previous hospitalization data starts from 1987. We relaxed our criterion of a three-year uniform hospitalizations prior to death to include up to five-year previous hospitalizations for the purpose of comparing results to our previous study [8].

\section{Exploratory analyses}

All exploratory analyses were performed post hoc in the subgroup of CV mortalities in individuals hospitalized for AMI. Since the timing of the hospitalization in relation to date of death may be important in modulating the susceptibility to short-term $\mathrm{O}_{3}$ exposure, we explored patterns of association by stratifying the time lapse between the last AMI hospitalization before death and death into four oneweek categories and six six-month categories before death and employed models for each time-category. Each timecategory included a separate model of daily $\mathrm{CV}$ deaths for individuals with AMI hospitalizations occurring within in specified time-period before date of death. For example, the first model included daily counts of $\mathrm{CV}$ deaths in a dataset in which $C V$ deaths had been preceded with last AMI hospitalizations within 0 to 6 days (week 0 ) before death. In this manner, we created datasets for each stratum and performed stratified analysis.

All estimates are expressed as percent increase risk of death risk with $95 \%$ confidence intervals per $10 \mu \mathrm{g} / \mathrm{m}^{3}$ increase in air pollution levels. All case-crossover and time series analyses were performed using Stata and R, respectively.

\section{Results}

A total of 159, $905 \mathrm{CV}$ and respiratory deaths were observed in Stockholm County from 1990 to 2010. We observed 6 times more $\mathrm{CV}$ deaths compared to respiratory deaths with a slight majority occurring in women (Table 1). The average age at the time of $\mathrm{CV}$ death was 77 years in men and 84 years in women and at the time of respiratory death 79 years in men and 82 years in women.

Average concentrations of all measured pollutants were low by international comparison (Table 2). Ozone measurements showed a near-normal distribution with sizable temporal variability whereas other pollutants demonstrated right-skewed distributions. Ozone was moderately positively correlated with $\mathrm{PM}_{10}$, and negatively correlated with $\mathrm{NO}_{2}$ and $\mathrm{NO}_{\mathrm{x}}$. Ozone and temperature were also moderately correlated (Table 3 ).

We observed associations between 8-h maximum $\mathrm{O}_{3}$ levels and $\mathrm{CV}$ mortality for both averaging periods with narrower confidence intervals for 8-h maximum $\mathrm{O}_{3}$ averaged over 2 days before death and similar estimates in both in time series analysis and case-crossover analyses (Table 4). No associations were observed between average $\mathrm{PM}_{2.5}$, $\mathrm{PM}_{10}$, and $\mathrm{NO}_{2}$ levels and $\mathrm{CV}$ mortality regardless of averaging period or analyses method. In two-pollutant models, the association between $\mathrm{O}_{3}$ and $\mathrm{CV}$ mortality was slightly increased while estimates for $\mathrm{PM}_{2.5}, \mathrm{NO}_{2}$ and $\mathrm{NO}_{\mathrm{x}}$ remained non-significant (Additional file 1: Table S1). In the two-pollutant model with $\mathrm{PM}_{10}$, we observed a slightly stronger estimate for $\mathrm{O}_{3}\left(0.9 \%\right.$ increased risk per $10 \mu \mathrm{g} / \mathrm{m}^{3}$; $95 \%$ CI $0.2 \%, 1.6 \%$ ) and unexpectedly a decreased risk of CV mortality related to $\mathrm{PM}_{10}(-1.3 \%$; $95 \%$ CI: $-2.4 \%,-0.2 \%$, per $10 \mu \mathrm{g} / \mathrm{m}^{3}$ increment).

In further analyses, 2-day average $\mathrm{O}_{3}$ was associated with a higher $\mathrm{CV}$ mortality risk in individuals older than the median age (82 years old, 1.7\% (95\% CI 0.9\%, 2.4\%) compared with individuals equal to or below the median age $(0.6 \%$; $95 \%$ CI $-0.2 \%, 1.4 \%)$ with a $p$-value for interaction of 0.04 (Additional file 1: Table S2). Differences in $\mathrm{O}_{3}$ associations between men and women or deaths occurring in the warm or cold season were not as clear ( $p$-values for interaction 0 . 7 and 0.9 respectively).

Associations between 2-day $\mathrm{O}_{3}$ and $\mathrm{CV}$ mortality by categories of hospitalization demonstrated positive

Table 2 Distribution of air pollution concentrations and meteorological parameters in 2-day (lag 0-1) and 7-day average (lag 0-6), Stockholm, Sweden, 1990-2010

\begin{tabular}{|c|c|c|c|c|c|c|c|c|}
\hline \multirow[t]{2}{*}{ Parameters } & \multicolumn{4}{|c|}{ 2-day average } & \multicolumn{4}{|c|}{ 7-day average } \\
\hline & Mean (SD) & Min & Max & $\mathrm{IQR}$ & Mean (SD) & Min & Max & IQR \\
\hline $\mathrm{O}_{3}$ & $62.8(20)$ & 4.7 & 143.0 & 27.7 & $62.7(18)$ & 11.7 & 121.9 & 27.0 \\
\hline $\mathrm{PM}_{2.5}$ & $8.2(5)$ & 0.9 & 41.6 & 4.6 & $8.2(4)$ & 2.2 & 39.8 & 3.9 \\
\hline $\mathrm{PM}_{10}$ & $15.3(8)$ & 2.2 & 92.7 & 8.8 & $15.3(7)$ & 3.9 & 64.2 & 7.4 \\
\hline $\mathrm{NO}_{2}$ & $19.0(8)$ & 2.4 & 78.7 & 11.3 & $19.1(7)$ & 4.6 & 56.9 & 9.3 \\
\hline $\mathrm{NO}_{\mathrm{x}}$ & $26.9(18)$ & 2.5 & 404.4 & 18.3 & $27.1(15)$ & 5.1 & 239.4 & 16.3 \\
\hline Temp & $7.6(7)$ & -15.9 & 26.1 & 12.3 & - & - & - & - \\
\hline Rh & 74.7 (12) & 33.7 & 99.3 & 17.7 & - & - & - & - \\
\hline
\end{tabular}

$\mathrm{O}_{3}$ ozone, $P M_{2.5}$ mass concentration of particles $\leq 2.5 \mu \mathrm{m}$ in aerodynamic diameter, $P M_{10}$ mass concentration of particles $\leq 10 \mu \mathrm{m}$ in aerodynamic diameter, $N \mathrm{O}_{x}$ nitrogen oxides, $\mathrm{NO}_{2}$ nitrogen dioxide, Temp temperature, $\mathrm{Rh}$ relative humidity 
Table 3 Pearson correlation coefficients between air pollutants and meteorological parameters measured in Stockholm, Sweden, 1990-2010. Values above diagonal are for 7-day averages and below for 2-day averages

\begin{tabular}{|c|c|c|c|c|c|c|c|}
\hline $\begin{array}{l}\text { 7-day } \\
\text { 2-day }\end{array}$ & $\mathrm{O}_{3}$ & $\mathrm{PM}_{2.5}$ & $\mathrm{PM}_{10}$ & $\mathrm{NO}_{2}$ & $\mathrm{NO}_{x}$ & Temp & $\mathrm{Rh}$ \\
\hline$\overline{\mathrm{O}_{3}}$ & 1.00 & 0.26 & 0.47 & -0.34 & -0.43 & 0.50 & -0.57 \\
\hline $\mathrm{PM}_{2.5}$ & 0.24 & 1.00 & 0.74 & 0.26 & 0.20 & 0.02 & 0.02 \\
\hline $\mathrm{PM}_{10}$ & 0.41 & 0.74 & 1.00 & 0.17 & 0.09 & 0.03 & -0.23 \\
\hline $\mathrm{NO}_{2}$ & -0.32 & 0.23 & 0.23 & 1.00 & 0.90 & -0.37 & 0.09 \\
\hline $\mathrm{NO}_{x}$ & -0.40 & 0.17 & 0.16 & 0.88 & 1.00 & -0.34 & 0.11 \\
\hline Temp & 0.47 & 0.04 & 0.04 & -0.33 & -0.29 & 1.00 & -0.38 \\
\hline $\mathrm{Rh}$ & -0.60 & 0.04 & -0.24 & 0.18 & 0.10 & -0.38 & 1.00 \\
\hline
\end{tabular}

$\mathrm{O}_{3}$ ozone, $P M_{2.5}$ mass concentration of particles $\leq 2.5 \mu \mathrm{m}$ in aerodynamic diameter, $P M_{10}$ mass concentration of particles $\leq 10 \mu \mathrm{m}$ in aerodynamic diameter, $\mathrm{NO}_{x}$ nitrogen oxides, $\mathrm{NO}_{2}$ nitrogen dioxide, Temp temperature, $\mathrm{Rh}$ relative humidity

associations in individuals with previous hospitalizations for AMI and in individuals who had not been hospitalized between 0 to 2 years before cardiovascular death or who had never been hospitalized since 1987 (Fig. 1). Previous hospitalization for respiratory disease seemed to confer greater risk for $\mathrm{CV}$ death following $\mathrm{O}_{3}$ exposure in the case-crossover analyses, however this was not corroborated in the time series analysis method. No associations were observed between $\mathrm{O}_{3}$ exposure and $\mathrm{CV}$ death in individuals with prior hospitalizations for CVD other than AMI, diabetes or any other disease. Risk increases per $10 \mu \mathrm{g} / \mathrm{m}^{3} \mathrm{O}_{3}$ in AMI was roughly 2.5fold higher estimate than for all $\mathrm{CV}$ deaths. For example, in individuals with previous hospitalizations for AMI, a $10 \mu \mathrm{g} / \mathrm{m}^{3}$ increment of 2-day average 8-h maximum $\mathrm{O}_{3}$ increased the risk of $\mathrm{CV}$ mortality by $1.8 \%$ ( $95 \%$ CI $0.3 \%$, $3.0 \%)$ and $2.2 \%$ (95\% CI $0.8 \%, 3.6 \%)$ for time series and case-crossover respectively. Comparing case-crossover models with and without interaction terms indicated likely interaction by hospitalization category ( $p$-value for likelihood ratio test 0.02 ).

We further stratified individuals with previous AMI hospitalization based on the admission date of the last AMI in time series analyses. The risk of CV mortality following 2-day average $\mathrm{O}_{3}$ did not demonstrate a clear trend for hospitalization occurring the month immediate preceding death. Risk estimates among individuals with hospitalizations occurring 1-36 months were consistently positive (Fig. 2).

We observed stronger associations between 8-h maximum $\mathrm{O}_{3}$ levels and respiratory mortality in 0-6 day lag compared to $0-1$ day lag irrespective of analysis method (Table 4). We did not observe associations between average $\mathrm{PM}_{2.5}, \mathrm{PM}_{10}$, and $\mathrm{NO}_{2}$ levels and respiratory mortality for any averaging period. In two-pollutant models, associations between $\mathrm{O}_{3}$ exposure and respiratory mortality remained positive in the co-presence of $\mathrm{NO}_{2}$, and $\mathrm{NO}_{x}$ (Additional file 1: Table S1). In the two-pollutant model including $\mathrm{PM}_{2}$. 5 and $\mathrm{PM}_{10}$, the association for $\mathrm{O}_{3}$ became weaker and non-significant and the estimates for both particulate matter fractions were reduced.

In further exploratory analyses associations between 7day average $\mathrm{O}_{3}$ and respiratory mortality remained unchanged in models including a multiplicative term for $\mathrm{O}_{3}$ and sex, age, or season ( $p$-values for interaction $\geq 0.1$, Additional file 1: Table S3).

Associations between 7-day $\mathrm{O}_{3}$ exposure and respiratory mortality by previous hospitalization categories were similar in time series and case-crossover methods (Fig. 3). Positive associations were observed in individuals with previous hospitalization for COPD and other diseases, however; there was little support for effect modification

Table 4 Percent change in cardiovascular and respiratory mortality in all subjects associated with a $10 \mu \mathrm{g} / \mathrm{m}^{3}$ increase in 2 -day and 7-day average air pollution concentrations, respectively using time series and case-crossover design

\begin{tabular}{|c|c|c|c|c|c|}
\hline \multirow[t]{2}{*}{ Pollutant } & \multirow[t]{2}{*}{ Lags } & \multicolumn{2}{|l|}{ Time series } & \multicolumn{2}{|l|}{ Case-crossover } \\
\hline & & Cardiovascular mortality & Respiratory mortality & Cardiovascular mortality & Respiratory mortality \\
\hline \multirow[t]{2}{*}{$\mathrm{O}_{3}$} & 0-1 day & $0.7(0.1,1.3)$ & $1.1(-0.4,2.6)$ & $1.2(0.6,1.8)$ & $1.2(-0.2,2.7)$ \\
\hline & 0-6 day & $0.8(0.1,1.6)$ & $2.7(0.8,4.5)$ & $1.1(0.3,1.9)$ & $2.5(0.6,4.4)$ \\
\hline \multirow[t]{2}{*}{$\mathrm{PM}_{2.5}$} & 0-1 day & $0.0(-2.0,2.1)$ & $-0.1(-4.7,4.8)$ & $-0.2(-2.2,1.9)$ & $-0.2(-4,8,4.7)$ \\
\hline & 0-6 day & $-0.3(-2.9,2.4)$ & $-4.1(-9.9,2.1)$ & $0.4(-2.2,3.0)$ & $-8.1(-13,6,-2.3)$ \\
\hline \multirow[t]{2}{*}{$\mathrm{PM}_{10}$} & $0-1$ day & $-0.8(-1.8,0.2)$ & $0.3(-2.1,2.8)$ & $-1.0(-2.0,0.0)$ & $-0.2(-2.7,2.3)$ \\
\hline & 0-6 day & $-0.8(-2.1,0.6)$ & $-0.1(-3.3,3.2)$ & $-0.5(-2.0,0.9)$ & $-1.8(-5.0,1.5)$ \\
\hline \multirow[t]{2}{*}{$\mathrm{NO}_{2}$} & 0-1 day & $-0.6(-1.7,0.5)$ & $0.2(-2.4,2.9)$ & $-1.2(-2.3,0.0)$ & $0.2(-2,5,3.0)$ \\
\hline & 0-6 day & $0.3(-1.3,1.9)$ & $-2,3(-6.0,1.5)$ & $0.6(-1.1,2.3)$ & $-0.5(-4.4,3.5)$ \\
\hline \multirow[t]{2}{*}{$\mathrm{NO}_{x}$} & 0-1 day & $-0.1(-0.5,0.4)$ & $-0.1(-1.1,0.9)$ & $-0.4(-0.8,0.1)$ & $-0.1(-1,2,1.1)$ \\
\hline & 0-6 day & $0.1(-0.6,0.7)$ & $-1.3(-2.8,0.3)$ & $0.0(-0.6,0.7)$ & $-1.2(-2.8,0.4)$ \\
\hline
\end{tabular}

$\mathrm{O}_{3}$ ozone, $P M_{2.5}$ mass concentration of particles $\leq 2.5 \mu \mathrm{m}$ in aerodynamic diameter, $P M_{10}$ mass concentration of particles $\leq 10 \mu \mathrm{m}$ in aerodynamic diameter, $\mathrm{NO}_{x}$ nitrogen oxides, $\mathrm{NO}_{2}$ nitrogen dioxide 


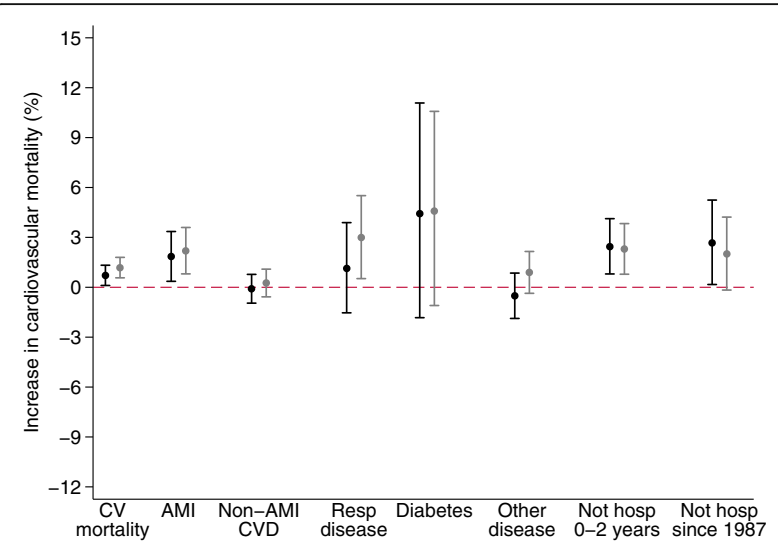

Fig. 1 Percent change (95\% confidence interval) in cardiovascular mortality associated with a $10 \mu \mathrm{g} / \mathrm{m}^{3}$ increase in 2-day average of 8-h maximum $\mathrm{O}_{3}$ concentrations by previous hospitalizations for acute myocardial infarction (AMI), other cardiovascular diseases excluding AMI (Non-AMI CVD), respiratory diseases, diabetes, other diseases, or by absence of any hospitalization between 0 to 3 years, or since 1987. All categories are mutually exclusive. Black markers indicate results from time series analyses and grey markers from case-crossover analyses by previous hospitalization ( $p$-value for likelihood ratio test 0.63).

Associations were similar when modeling the same averaging periods for temperature as for exposure as well as the use of 5-year rather than 3-year previous hospitalizations data for vulnerable population subgroups.

\section{Discussion}

Among all deaths in Stockholm County between 1990 and 2010 we observed associations between higher short-term

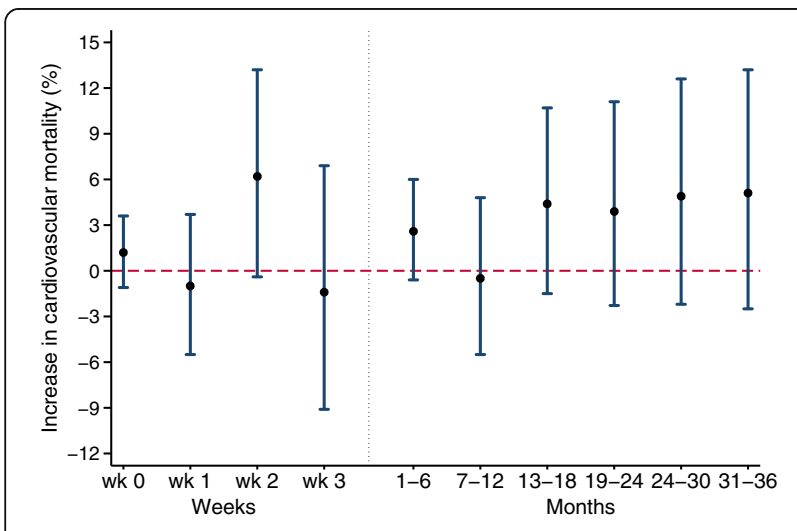

Fig. 2 Percent change (95\% confidence interval) in cardiovascular mortality associated with a $10 \mu \mathrm{g} / \mathrm{m}^{3}$ increase in 2-day average of 8-h maximum $\mathrm{O}_{3}$ concentrations in individuals with prior hospitalization for acute myocardial infarction. Individuals were stratified according to the time period between their last hospitalization and death. Strata included month 0 ( 0 -28 days before death) divided into 4 separate weeks, and preceding months (1-36) grouped into 6-month periods. All strata are mutually exclusive and results are from time series analysis

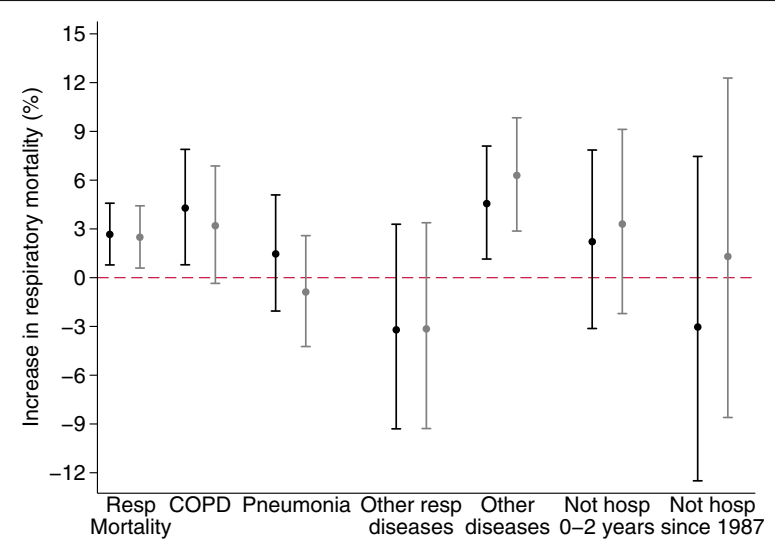

Fig. 3 Percent change (95\% confidence interval) in respiratory mortality associated with a $10 \mu \mathrm{g} / \mathrm{m}^{3}$ increase in 7-day average of 8-h maximum $\mathrm{O}_{3}$ concentrations by previous hospitalizations for chronic obstructive pulmonary disease (COPD), pneumonia, other respiratory diseases, other diseases, or by absence of any hospitalization between 0 to 3 years, or since 1987. All categories are mutually exclusive. Black markers indicate results from time series analyses and grey markers from case-crossover analyses

concentrations of $\mathrm{O}_{3}$ and $\mathrm{CV}$ and respiratory mortality. Estimates were higher for respiratory than for CV mortality. Associations between $\mathrm{O}_{3}$ and $\mathrm{CV}$ mortality were relatively stronger in individuals hospitalized for AMI as well as for those individuals who had not been hospitalized for any disease. Associations between $\mathrm{O}_{3}$ and respiratory mortality were not affected by individuals' previous hospitalizations. We did not observe associations between $\mathrm{PM}_{2.5}, \mathrm{PM}_{10}, \mathrm{NO}_{2}$ and $\mathrm{NO}_{\mathrm{x}}$ levels and $\mathrm{CV}$ or respiratory mortality.

Associations for $\mathrm{CV}$ mortality were similar for both averaging periods of 8-h maximum $\mathrm{O}_{3}$. In contrast, we observed higher estimates for the association between 7day average 8-h maximum $\mathrm{O}_{3}$ and respiratory mortality compared to the shorter averaging period of 2-day. This pattern is largely consistent with the The Air Pollution and Health: a European Approach study that also reported stronger estimates for the association between $\mathrm{O}_{3}$ and respiratory mortality in longer lags ( $0-20$ day) as compared to shorter lags ( 0 and $0-1$ day), while the opposite was observed for $\mathrm{CV}$ mortality [11]. This implies that exposure to high $\mathrm{O}_{3}$ levels has a more immediate effect on triggering $\mathrm{CV}$ mortality, whereas the effect on respiratory mortality might require longer $\mathrm{O}_{3}$ exposure and other biological processes [11].

Previous studies have reported positive associations between $\mathrm{PM}_{2.5}, \mathrm{PM}_{10}, \mathrm{NO}_{2}$ and $\mathrm{NO}_{\mathrm{x}}$ and $\mathrm{CV}$ and respiratory mortality $[12,13]$. We found no evidence of associations for these pollutants in our study. Possible explanations may include low concentrations and the use of single monitors to assess pollutants with more spatial heterogeneity than $\mathrm{O}_{3}$. 
Little research has been conducted on identifying individuals susceptible to the harmful effects of air pollution based on previous CVD, however, our results are generally concordant with results from the existing studies. In our previous study from Stockholm [8], we observed higher total mortality in association with 8-h maximum $\mathrm{O}_{3}$ exposure in individuals with previous AMI compared to the full study population. Risk estimates are similar in the current study investigating CV mortality (1.7\% vs $1.8 \%)$. A study from Italy [6], also investigating total mortality, reported non-significant associations between 0 and 5 day 8-h maximum $\mathrm{O}_{3}$ and total mortality in individuals with previous AMI hospitalization (2.6\% increase risk per $10 \mu \mathrm{g} / \mathrm{m}^{3}$ 95\% CIs: $\left.-1.0 \%, 6.4 \%\right)$. However, diabetes was the pre-existing condition that conferred the greatest susceptibility to ozone, results which were not confidently confirmed in our analyses. Another study from Italy [9] investigating a more specific outcome, reported a borderline significant association between $\mathrm{O}_{3}$ exposure and out-ofhospital coronary deaths in individuals who had previous hospitalizations for ischemic heart disease ( $p$-value 0.059) which lends some support to our finding that suggest susceptibility to CV mortality in individuals with previous hospitalization to AMI. In contrast to our results, a large multicity study from the US using secondary cause of death as a proxy for pre-existing disease reported no increased susceptibility between $\mathrm{O}_{3}$ and mortality for atherosclerotic conditions, however additional susceptibility was observed for atrial fibrillation [3].

Our results suggest that association between $\mathrm{O}_{3}$ exposure and $\mathrm{CV}$ death in individuals with AMI hospitalizations appeared to be driven mainly by AMI hospitalizations more than 1 month preceding death. Studies have reported the highest post AMI mortality within the first 28 days [14]. During this time patients are typically under intensive medication and the increased antithrombotic medication may potentially reduce the harmful effects of $\mathrm{O}_{3}$. We may also speculate that other risks are more dominant within the first month post-AMI compared to the effect of $\mathrm{O}_{3}$. In addition, individuals are plausibly less frequently outdoors during the first month after an AMI and they may be less exposed to outdoor $\mathrm{O}_{3}$ concentrations. Hence, the increased risk observed in individuals with AMIs more than 1 month preceding death may reflect an increased exposure to $\mathrm{O}_{3}$ or less exposure misclassification.

Out-of-hospital CV deaths with no previous hospitalization for any causes demonstrated an indication of association with $\mathrm{O}_{3}$ exposure. It is likely that many of these individuals had an undiagnosed (and untreated) underlying condition that made them susceptible to $\mathrm{O}_{3}$ exposure. Epidemiological studies as well as autopsy series reported presence of structural heart disease, including coronary artery disease, in $50-95 \%$ of adults who suffered sudden cardiac death without previously known heart disease [15, 16]. In our study, CV death in individuals not hospitalized since 1987 were relatively younger (mean age 73 years) compared to the rest of the individuals. Younger individuals are more likely to be exposed to higher $\mathrm{O}_{3}$ levels through outdoor physical activity. In addition, in a previous study in Stockholm based on a cardiac arrest registry, we reported associations between higher short-term exposure to $\mathrm{O}_{3}$ and risk of out-of-hospital cardiac arrest [17], largely supporting the theory that the previously non-hospitalized deaths may reflect cardiac arrests in individuals with latent heart disease.

Ozone exposure has been consistently associated with respiratory mortality in several studies including large multi-city studies $[1,4,11,18-20]$. Associations have generally been reported from exposure periods between 0 and 1 and $0-5$ day lags and our estimates of $2.7 \%$ higher risk per $10 \mu \mathrm{g} / \mathrm{m}^{3} 7$-day exposure are in line with previously reported estimates. In addition to studies investigating $\mathrm{O}_{3}$ exposure and respiratory mortality, several studies have reported associations between $\mathrm{O}_{3}$ exposure and hospital admission for COPD [21-26].

Few previous studies have investigated the role of previous hospitalizations for respiratory disease on association between $\mathrm{O}_{3}$ and respiratory mortality. None of these have reported increased risk of death in individuals with previous respiratory hospitalizations $[3,6,9]$. In individuals with COPD hospitalizations, the timing of hospitalizations did not seem important in determining the susceptibility to $\mathrm{O}_{3}$ in relation to respiratory mortality.

We observed an increased risk of CV mortality among elderly following short-term exposure to $\mathrm{O}_{3}$. Other studies have also reported elderly as susceptible to the detrimental effects of $\mathrm{O}_{3}$ exposure $[6,8,9,27]$. We did not observe risk difference in men or women, while, a majority of studies have reported stronger associations between $\mathrm{O}_{3}$ exposure and CV outcomes in women $[3,6]$, although some inconsistencies remain [8] and studies investigating specific pathophysiological mechanisms are lacking [3]. Furthermore, we observed no evidence to support differing risk to $\mathrm{O}_{3}$-related risk of respiratory mortality by age and sex.

Ozone has a strong seasonal trend with high levels in warm period of the year and low level in cold period. In previous studies stronger associations have been demonstrated for the warm period of the year between $\mathrm{O}_{3}$ exposure and $\mathrm{CV}$ and respiratory mortality $[6,11,19,28]$, while, we did not observe seasonal influence on our risk estimates.

Inflammation and oxidative stress are integral components in the pathogenic process of respiratory [29] but also of atherosclerotic heart disease [30]. Ozone has a high oxidative potential and has in animal studies been shown to adversely react with airway epithelium inducing smooth muscle hyperplasia and dysfunction, and contribute to subsequent bronchial hyperresponsiveness 
[31]. An experimental study in healthy young adults reported increased inflammatory markers and decreased lung function measures following exposure to $\mathrm{O}_{3}$ [32]. Other experimental studies have reported increase in levels of inflammatory markers such as pro-inflammatory cytokines and C-reactive protein after exposure to $\mathrm{O}_{3}$ [33-36]. Ozone exposure has also been associated with alterations in the autonomic nervous system [37-41] and changes in blood pressure in individuals with [42] and without [43] previous cardiovascular disease. In addition to possibly contributing to the risk of developing atherosclerotic heart disease, $\mathrm{O}_{3}$ exposure may be involved in the exacerbation of these disease processes in post-AMI patients.

This study has several limitations. Like most epidemiological studies, we did not have information on individualspecific $\mathrm{O}_{3}$ exposure, instead we used ambient concentrations from a single monitoring station as exposure estimates for the entire population. Moreover, we did not have data regarding the time spent indoors, activity pattern, and location of residents, which could introduce potential misclassification; however, this type of misclassification is likely non-differential and would bias towards the null. Although our dataset included possibility for multiple hospitalizations for several diseases we created mutually exclusive subpopulations for comparison purposes and could not take into account the full complexity of presence of multiple diseases. Our study was based exclusively on fatalities occurring during the study period and therefore precluded studying associations of non-fatal disease incidence. The major strength of our study is the full coverage of the mortality and previous hospitalization registries. These registries have been shown to have a high validity [10]. Although some level of inaccuracy is still expected in the registry data, it is not expected to vary with our exposure and thus the net result would be an underestimation of the observed estimates.

\section{Conclusion}

Short-term $\mathrm{O}_{3}$ exposure was associated with $\mathrm{CV}$ and respiratory mortality. We found suggestive evidence of increased of susceptibility for CV mortality following shortterm exposure to $\mathrm{O}_{3}$ in individuals previously hospitalized for AMI and observed an indication of higher risks in individuals with out-of-hospital CV death as their first presentation of disease. These results may support the consideration of increased risk in large susceptible subpopulations in health impact assessments of $\mathrm{O}_{3}$ exposure.

\section{Additional file}

Additional file 1: Table S1. Two pollutant models. Percent change in cardiovascular and respiratory mortality associated with a $10 \mu \mathrm{g} / \mathrm{m}^{3}$ increase in 2-day and 7-day average air pollution concentrations, respectively in time series analyses. Table S2. Percent change in cardiovascular mortality associated with a $10 \mu \mathrm{g} / \mathrm{m}^{3}$ increase in 2-day average 8-h maximum $\mathrm{O}_{3}$ concentrations by season, age, and sex in case-crossover analyses. Table S3. Percent change in respiratory mortality associated with a $10 \mu \mathrm{g} / \mathrm{m}^{3}$ increase in 7-day average 8-h maximum $\mathrm{O}_{3}$ concentrations by season, age, and sex in case-crossover analyses. (DOCX 25 kb)

\section{Abbreviations}

AMI: Acute myocardial infarction; Cl: Confidence interval; COPD: Chronic obstructive pulmonary disease; CV: Cardiovascular; CVD: Cardiovascular disease; Df: Degrees of freedom; ICD-10: International Classification of Diseases, Tenth Revision; ICD-9: International Classification of Diseases, Ninth Revision; IQR: Interquartile Range; $\mathrm{NO}_{2}$ : Nitrogen Dioxide; $\mathrm{NO}_{x}$ : Nitrogen dioxides; $\mathrm{O}_{3}$ : Ozone; $\mathrm{PM}_{10}$ : Particles with aerodynamic diameter smaller than $10 \mu \mathrm{m} ; \mathrm{PM}_{2.5}$ : Particles with aerodynamic diameter smaller than $2.5 \mu \mathrm{m}$; SD: Standard Deviation

\section{Funding}

AR is supported by Karolinska Institutet's fund for doctoral students (KID). PLL is supported by funding from the Swedish Research Council for Health, Working Life and Welfare (FORTE), Swedish Society for Medical Research (SSMF) and Karolinska Institute's Strategic Research Area in Epidemiology (SFO-EPI).

\section{Availability of data and materials}

Available on request.

\section{Authors' contributions}

AR was responsible for the practical work of the project including planning, management and analysis of the data which was supervised by PLL. AR wrote the first version of the manuscript. MD was involved in the planning of the project. TL provided statistical expertise. PLL designed the study and provided medical expertise. All authors contributed to the interpretation of the data, revised the manuscript, and approved the final manuscript and this submission.

Ethics approval and consent to participate

This study was approved by the Regional ethical board at the Karolinska Institutet (file number 2011/1815-31/1).

\section{Competing interests}

The authors declare that they have no competing interests.

\section{Publisher's Note}

Springer Nature remains neutral with regard to jurisdictional claims in published maps and institutional affiliations.

\section{Author details}

${ }^{1}$ Institute of Environmental Medicine, Karolinska Institutet, Nobels väg 13 | Box 210 |, SE-171 77 Stockholm, Sweden. ${ }^{2}$ Center for Occupational and Environmental Medicine, Stockholm County Council, Solnavägen 4, 11365 Stockholm, Sweden. ${ }^{3}$ Department of Cardiology, Danderyd Hospital,

Stockholm, Sweden.

Received: 8 November 2017 Accepted: 5 April 2018

Published online: 13 April 2018

\section{References}

1. Jerrett M, Burnett RT, Pope CA 3rd, Ito K, Thurston G, Krewski D, Shi Y, Calle E, Thun M. Long-term ozone exposure and mortality. N Engl J Med. 2009; 360(11):1085-95.

2. Coogan PF, White LF, Yu J, Brook RD, Burnett RT, Marshall JD, Bethea TN, Rosenberg L, Jerrett M. Long-term exposure to NO2 and ozone and hypertension incidence in the black Women's Health Study. Am J Hypertens. 2017;30(4):367-72.

3. Medina-Ramon M, Schwartz J. Who is more vulnerable to die from ozone air pollution? Epidemiology (Cambridge, Mass). 2008;19(5):672-9.

4. Goldberg MS, Burnett RT, Brook J, Bailar JC, Valois M-F, Vincent R. Associations between daily cause-specific mortality and concentrations of ground-level ozone in Montreal, Quebec. Am J Epidemiol. 2001;154(9):817-26.

5. Bell ML, Dominici F, Samet JM. A meta-analysis of time-series studies of ozone and mortality with comparison to the national morbidity, mortality, and air pollution study. Epidemiology (Cambridge, Mass). 2005;16(4):436-45. 
6. Stafoggia M, Forastiere F, Faustini A, Biggeri A, Bisanti L, Cadum E, Cernigliaro A, Mallone S, Pandolfi P, Serinelli M, et al. Susceptibility factors to ozone-related mortality: a population-based case-crossover analysis. Am J Respir Crit Care Med. 2010;182(3):376-84.

7. Buka I, Koranteng S, Osornio-Vargas AR. The effects of air pollution on the health of children. Paediatr Child Health. 2006;11(8):513-6.

8. Bero Bedada G, Raza A, Forsberg B, Lind T, Ljungman P, Pershagen G, Bellander T. Short-term exposure to ozone and mortality in subjects with and without previous cardiovascular disease. Epidemiology (Cambridge, Mass). 2016;27(5):663-9.

9. Nuvolone D, Balzi D, Pepe P, Chini M, Scala D, Giovannini F, Cipriani F, Barchielli A. Ozone short-term exposure and acute coronary events: a multicities study in Tuscany (Italy). Environ Res. 2013;126:17-23.

10. Ludvigsson JF, Andersson E, Ekbom A, Feychting M, Kim JL, Reuterwall C, Heurgren M, Olausson PO. External review and validation of the Swedish national inpatient register. BMC Public Health. 2011;11:450.

11. Zanobetti A, Schwartz J. Mortality displacement in the association of ozone with mortality: an analysis of 48 cities in the United States. Am J Respir Crit Care Med. 2008;177(2):184-9.

12. Brook RD, Rajagopalan S, Pope CA 3rd, Brook JR, Bhatnagar A, Diez-Roux AV, Holguin F, Hong Y, Luepker RV, Mittleman MA, et al. Particulate matter air pollution and cardiovascular disease: an update to the scientific statement from the American Heart Association. Circulation. 2010;121(21):2331-78.

13. Baccini M, Mattei A, Mealli F, Bertazzi PA, Carugno M. Assessing the short term impact of air pollution on mortality: a matching approach. Environ Health. 2017;16(1):7.

14. Salomaa $V$, Niemela M, Miettinen $H$, Ketonen $M$, Immonen-Raiha $P$, Koskinen S, Mahonen M, Lehto S, Vuorenmaa T, Palomaki P, et al. Relationship of socioeconomic status to the incidence and prehospital, 28-day, and 1-year mortality rates of acute coronary events in the FINMONICA myocardial infarction register study. Circulation. 2000;101(16):1913-8.

15. Chugh SS, Kelly KL, Titus JL. Sudden cardiac death with apparently normal heart. Circulation. 2000;102(6):649-54

16. Kannel WB, Schatzkin A. Sudden death: lessons from subsets in population studies. J Am Coll Cardiol. 1985;5(6 Suppl):141B-9B.

17. Raza A, Bellander T, Bero-Bedada G, Dahlquist M, Hollenberg J, Jonsson M, Lind T, Rosenqvist M, Svensson L, Ljungman PL. Short-term effects of air pollution on out-of-hospital cardiac arrest in Stockholm. Eur Heart J. 2013;35(13):861-8.

18. Zhang Y, Huang W, London SJ, Song G, Chen G, Jiang L, Zhao N, Chen B, Kan H. Ozone and daily mortality in Shanghai, China. Environ Health Perspect. 2006;114(8):1227-32.

19. Samoli E, Zanobetti A, Schwartz J, Atkinson R, LeTertre A, Schindler C, Perez L, Cadum E, Pekkanen J, Paldy A, et al. The temporal pattern of mortality responses to ambient ozone in the APHEA project. J Epidemiol Community Health. 2009;63(12):960-6.

20. Anderson HR, Atkinson RW, Peacock J, Marston L, Konstantinou K: Metaanalysis of time-series studies and panel studies of particulate matter (PM) and ozone (O3): report of a WHO task group. 2004.

21. Anderson HR, Spix C, Medina S, Schouten JP, Castellsague J, Rossi G, Zmirou D, Touloumi G, Wojtyniak B, Ponka A, et al. Air pollution and daily admissions for chronic obstructive pulmonary disease in 6 European cities: results from the APHEA project. Eur Respir J. 1997;10(5):1064-71.

22. Medina-Ramon M, Zanobetti A, Schwartz J. The effect of ozone and PM10 on hospital admissions for pneumonia and chronic obstructive pulmonary disease: a national multicity study. Am J Epidemiol. 2006;163(6):579-88.

23. Ghozikali MG, Mosaferi M, Safari GH, Jaafari J. Effect of exposure to O(3), $\mathrm{NO}(2)$, and $\mathrm{SO}(2)$ on chronic obstructive pulmonary disease hospitalizations in Tabriz, Iran. Environ Sci Pollut Res Int. 2015;22(4):2817-23.

24. Ghanbari Ghozikali M, Heibati B, Naddafi K, Kloog I, Oliveri Conti G, Polosa R, Ferrante M. Evaluation of Chronic Obstructive Pulmonary Disease (COPD) attributed to atmospheric O3, NO2, and SO2 using air Q model (2011-2012 year). Environ Res. 2016;144(Pt A):99-105.

25. Ko FW, Tam W, Wong TW, Chan DP, Tung AH, Lai CK, Hui DS. Temporal relationship between air pollutants and hospital admissions for chronic obstructive pulmonary disease in Hong Kong. Thorax. 2007;62(9):780-5.

26. Li J, Sun S, Tang R, Qiu H, Huang Q, Mason TG, Tian L. Major air pollutants and risk of COPD exacerbations: a systematic review and meta-analysis. Int J Chron Obstruct Pulmon Dis. 2016;11:3079-91.

27. Ruidavets J-B, Cournot M, Cassadou S, Giroux M, Meybeck M, Ferrières J. Ozone air pollution is associated with acute myocardial infarction. Circulation. 2005;111(5):563.
28. Peng RD, Samoli E, Pham L, Dominici F, Touloumi G, Ramsay T, Burnett RT, Krewski D, Le Tertre A, Cohen A, et al. Acute effects of ambient ozone on mortality in Europe and North America: results from the APHENA study. Air Qual Atmos Health. 2013;6(2):445-53.

29. Chung KF, Adcock IM. Multifaceted mechanisms in COPD: inflammation, immunity, and tissue repair and destruction. Eur Respir J. 2008;31(6):1334-56.

30. Uno K, Nicholls SJ. Biomarkers of inflammation and oxidative stress in atherosclerosis. Biomark Med. 2010;4(3):361-73.

31. Li F, Wiegman C, Seiffert JM, Zhu J, Clarke C, Chang Y, Bhavsar P, Adcock I, Zhang J, Zhou X, et al. Effects of $\mathrm{N}$-acetylcysteine in ozone-induced chronic obstructive pulmonary disease model. PLoS One. 2013;8(11):e80782.

32. Kim CS, Alexis NE, Rappold AG, Kehrl H, Hazucha MJ, Lay JC, Schmitt MT, Case M, Devlin RB, Peden DB, et al. Lung function and inflammatory responses in healthy young adults exposed to 0.06 ppm ozone for 6.6 hours. Am J Respir Crit Care Med. 2011;183(9):1215-21.

33. Devlin RB, Duncan KE, Jardim M, Schmitt MT, Rappold AG, Diaz-Sanchez D. Controlled exposure of healthy young volunteers to ozone causes cardiovascular effects. Circulation. 2012;126(1):104-11.

34. Thompson AM, Zanobetti A, Silverman F, Schwartz J, Coull B, Urch B, Speck M, Brook JR, Manno M, Gold DR. Baseline repeated measures from controlled human exposure studies: associations between ambient air pollution exposure and the systemic inflammatory biomarkers IL-6 and fibrinogen. Environ Health Perspect. 2010;118(1):120-4.

35. Peters A, von Klot S, Heier M, Trentinaglia I, Cyrys J, Hormann A, Hauptmann M, Wichmann HE, Lowel H. Particulate air pollution and nonfatal cardiac events. Part I. Air pollution, personal activities, and onset of myocardial infarction in a case-crossover study. Res Rep (Health Effects Institute). 2005; (124):1-66. discussion 67-82, 141-148

36. Chuang KJ, Chan CC, Su TC, Lee CT, Tang CS. The effect of urban air pollution on inflammation, oxidative stress, coagulation, and autonomic dysfunction in young adults. Am J Respir Crit Care Med. 2007;176(4):370-6.

37. Jia X, Song X, Shima M, Tamura K, Deng F, Guo X. Acute effect of ambient ozone on heart rate variability in healthy elderly subjects. J Expo Sci Environ Epidemiol. 2011;21(5):541-7.

38. Shields KN, Cavallari JM, Hunt MJ, Lazo M, Molina M, Molina L, Holguin F. Traffic-related air pollution exposures and changes in heart rate variability in Mexico City: a panel study. Environ Health. 2013;12:7.

39. Zanobetti A, Gold DR, Stone PH, Suh HH, Schwartz J, Coull BA, Speizer FE. Reduction in heart rate variability with traffic and air pollution in patients with coronary artery disease. Environ Health Perspect. 2010;118(3):324-30.

40. Weichenthal S, Kulka R, Dubeau A, Martin C, Wang D, Dales R. Traffic-related air pollution and acute changes in heart rate variability and respiratory function in urban cyclists. Environ Health Perspect. 2011;119(10):1373-8.

41. Arjomandi M, Wong $\mathrm{H}$, Donde A, Frelinger J, Dalton S, Ching W, Power K, Balmes JR. Exposure to medium and high ambient levels of ozone causes adverse systemic inflammatory and cardiac autonomic effects. Am J Phys Heart Circ Phys. 2015;308(12):H1499-509.

42. Zanobetti A, Canner MJ, Stone PH, Schwartz J, Sher D, Eagan-Bengston E, Gates KA, Hartley LH, Suh H, Gold DR. Ambient pollution and blood pressure in cardiac rehabilitation patients. Circulation. 2004;110(15):2184-9.

43. Chuang KJ, Yan YH, Cheng TJ. Effect of air pollution on blood pressure, blood lipids, and blood sugar: a population-based approach. J Occup Environ Med. 2010;52(3):258-62.

\section{Ready to submit your research? Choose BMC and benefit from:}

- fast, convenient online submission

- thorough peer review by experienced researchers in your field

- rapid publication on acceptance

- support for research data, including large and complex data types

- gold Open Access which fosters wider collaboration and increased citations

- maximum visibility for your research: over $100 \mathrm{M}$ website views per year

At BMC, research is always in progress.

Learn more biomedcentral.com/submissions 